\title{
EFFECT OF MICROSTRUCTURE AND MECHANICAL PROPERTIES OF FRICTION STIR WELDED DISSIMILAR AA5083-AA6061 ALUMINIUM ALLOY JOINTS
}

\author{
Buddi Manohar ${ }^{1}$, Satishkumar. $\mathbf{P}^{2}$, Aruri Devaraju ${ }^{3}$ \\ ${ }^{I}$ Student (PG), Department of Mechanical Engineering, SR Engineering College, Ananthasagar, Warangal T.S. - 506 \\ 371, India \\ ${ }^{2}$ Associate professor, Department of Mechanical Engineering, SR Engineering College, Ananthasagar, Warangal T.S. \\ - 506 371, India \\ ${ }^{3}$ Assistant professor, Department of Mechanical Engineering, SR Engineering College, Ananthasagar, Warangal T.S. \\ -506371, India
}

\begin{abstract}
Friction Stir Welding (FSW) is a solid state welding process. In particular, it can be used to join high-strength aerospace aluminum and other metallic alloys that are hard to weld by conventional fusion welding. It was performed on $5 \mathrm{~mm}$ thicknessAA6061 and AA5083 dissimilar Aluminum alloys. Aluminum alloy light weight, softer, tendency to bend easily, cost effective in terms of energy requirements so aluminum alloy has selected in this FSW technique. In this welding when two metals are joined with the help of heat generated by rubbing metals against each other. The friction stir welding is mostly used for joining aluminum alloys. The main defects occurring in this welding are holes, material flow rate. These defects are mainly caused due to improper selection of welding parameters. In this project the mechanical properties of FSW dissimilar aluminum alloy AA5083 and AA6061has tested with the help of universal testing machine, hardness testing by Vickers hardness at various zones of the welded joints. In this experimental the testing of mechanical properties based on the input parameters such as rotational speed, tool speed and axial force with proper welding parameters. Finally, the experimental results will be compared with microstructures are analyzed by optical microscope. It is observed that the grain size is decreased in friction stir welding with circle with threaded pin profile. Also have better mechanical properties and these $S$ properties have been correlated with microstructures. Higher mechanical properties are obtained with square pin profile tool at a rotation speed of $1400 \mathrm{rpm}$ and welding speed of $60 \mathrm{~mm} / \mathrm{min}$.
\end{abstract}

Keywords: Friction Stir Welding 6061 And 5083 Aluminum Alloys, Tool Rotational Speed, Welding Speed, Mechanical Properties, Microstructure.

\section{INTRODUCTION}

The Invention of friction stir welding is done at uk welding institute in 1991 and the process is solid state metal joining permanent process. Friction Stir welding is a new solid state joining method offering several advantages over conventional welding methods, including better mechanical properties, low residual stress and reduced occurrence of defects. A rotating tool consisting of a shoulder and a probe is plunged into the joint and traversed along the joint line to form a weld. Fig-1 shows the schematic diagram of FSW. A typical friction stir weld consists of a thermo-mechanicallyaffected zone which includes dynamically recrystallized zone and the extensively deformed but not recrystallized surrounding region, the heat affected zone and the unaffected base material. AA6061\&AA5083 The Process deals with two dissimilar metals There is a significance to choose these materials as they are easily weldable ,machinable good corrosion characterstics . AA6061 has good creep resistance and is a medium strength alloy. This alloy is ideal for high integrity casting operating at ambient temperatures or up to $300^{\circ} \mathrm{F}$.
The welds are created by the combined action of frictional heating and mechanical deformation due to a rotating tool. The maximum temperature reached is of the order of 0.8 of the melting temperature. The micro structure of friction stir welding depends in detail on the tool design, the rotation and translation speeds, the applied pressure and the characteristics of the material being joined. The effect of these process parameter are studied in this project

\subsection{Tool Geometry}

The crucial part in this work was to design an experimental setup which would fit in the available machine tool. Understanding the tool design plays a very important role in friction stir welding. The diameter and height of the pin equal to the thickness of the sheets processed i.e., $8 \mathrm{~mm}$. The forces generated using this tool especially during the penetration of the tool in to the work piece, were very high and caused excessive machine vibration. The vertical 
motion towards the bottom of the weld is too low due to the lack of the threads. Then the pin of the tool is changed. A threaded cylindrical tool and tapered hexagonal tools are used in order to reduce the initial high forces during plunging operation.

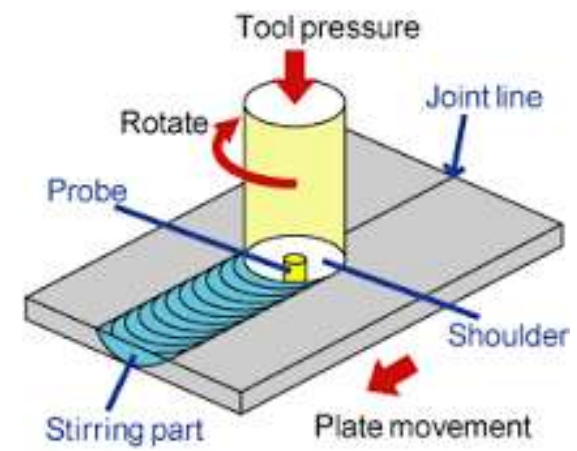

Fig. 1.Schematic drawing of friction stir welding

\section{LITERATURE REVIEW}

The Analysis made by Indira Rani (2011) on Experimental investigation of friction stir welding of dissimilar welding of AA 5083 and AA 6061 Aluminium alloys and concluded that the Welding speed and Tool rotational speed are the key parameters for friction stir welding.

N. T.Kumbharet. al. 2008The author said that during FSW with al 6061 alloy extensive deformation is experienced nugget zone(NG) and the progressed microstructure strongly affects the mechanical properties of joint.

C. Vidal, V. Infante, P. Pecas, P. Vilaca, has made a conclusion by the Application of Taguchi method in the optimization of Friction stir welding parameters of an aeronautics Aluminum Alloy, Adv. Materials Manufacturing \& characterization. 3 (2013): 21-26

\section{EXPERIMENTAL WORK}

Initially a base metal of $5 \mathrm{~mm}$ thickness of AA5083-AA 6061 aluminium alloys was welded as but joint. These are welded under vertical milling machine having $1 \mathrm{HP}$ motor and $3000 \mathrm{rpm}$.

we have chosen $\mathrm{H} 13$ tool steel as it has Non-deforming characteristics and having high hot hardness. Specifications of tool shoulder and pin used are $24 \mathrm{~mm}, 8 \mathrm{~mm}$, and length of pin $4.7 \mathrm{~mm}$.A constant axial force of $5 \mathrm{KN}$ has been applied and taken tool tilt angle $\left(1^{0}\right)$ with three rotational and welding speeds at different tool profiles (square, circle with thread and taper with thread) for remaining all FSW joints. During FSW the welding and after welding the specimens were exposed to normal cooling(atmosphere or room temperature). After the completion of FSW specimens were cut for different tests(tensile test, impact test(charpy), micro hardness, and micro structure) as per ASTM standards. After weld specimens made they were go for test machines.
Tensile specimens on universal testing machine, micro hardness on Vickers hardness machine, charphy test on impact machine and microstructure on optical microscope was carried. The schematic diagram of selection of samples for testing is shown in fig. 3 and fig. 4 .

After FSW, micro structural observations were carried out at the cross section of nugget zone of weldments normal to the FSP direction, mechanically polished and etched with Keller's reagent $(2 \mathrm{ml} \mathrm{HF}, 3 \mathrm{ml} \mathrm{HCl}, 20 \mathrm{ml} \mathrm{HNO} 3$ and 175 $\mathrm{ml} \mathrm{H} 2 \mathrm{O}$ ) by employing optical microscope (OM). Grain size is measured as per ASTM E112-13 standards. The tensile test was conducted with the help of a computer controlled universal testing machineat a cross head speed of 0.5 $\mathrm{mm} / \mathrm{min}$. Micro hardness tests were carried out at the cross section of nugget zone by using Vickers digital microhardness tester.

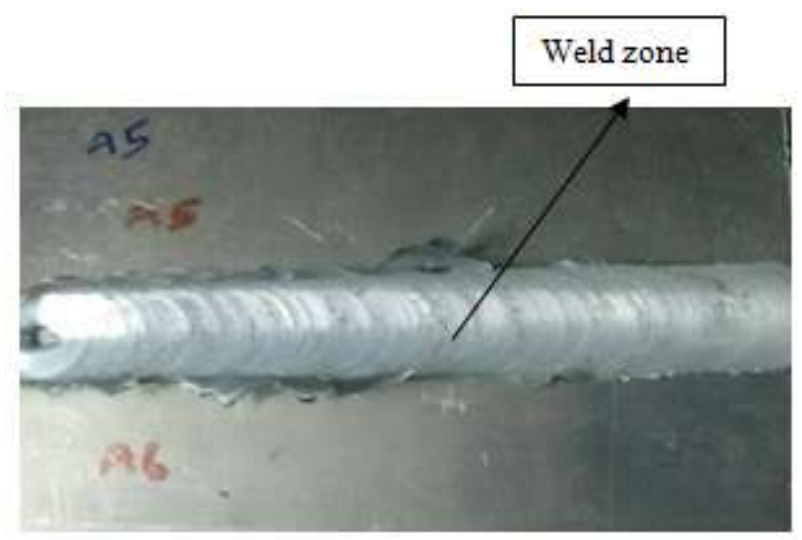

Fig.2. Aluminum alloy Friction stir weldment.

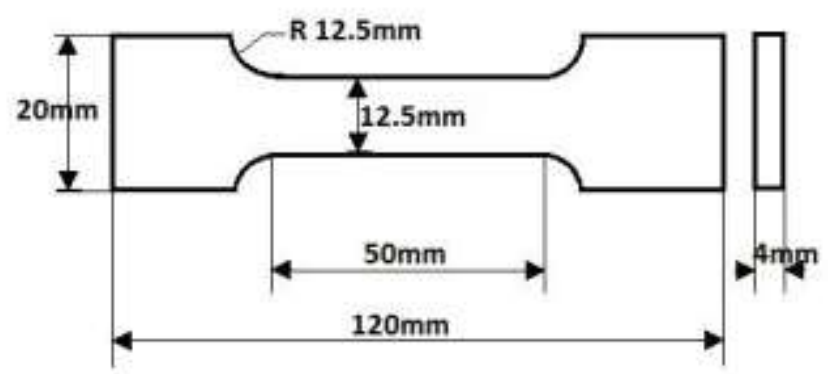

Fig.3 Schematic sketch of selection of sample for testing

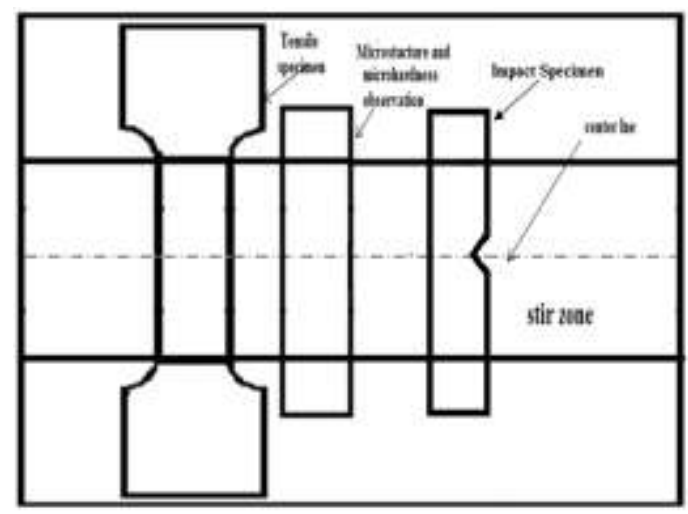

Fig.4. Schematic sketch of selection of samples for testing 
Table 1.Friction stirWelding process parameters

\begin{tabular}{|l|l|l|l|l|}
\hline $\begin{array}{l}\text { Specim } \\
\text { en }\end{array}$ & $\begin{array}{l}\text { Tool } \\
\text { profile }\end{array}$ & $\begin{array}{l}\text { Rotationa } \\
\text { l speed } \\
(\mathrm{rpm})\end{array}$ & $\begin{array}{l}\text { Welding } \\
\text { speed(mm/mi } \\
\text { n) }\end{array}$ & $\begin{array}{l}\text { Tilt } \\
\text { angle }\end{array}$ \\
\hline 1. & Square & 1400 & 60 & $1^{0}$ \\
\hline 2. & $\begin{array}{l}\text { Cylindri } \\
\text { cal with } \\
\text { thread }\end{array}$ & 900 & 40 & $1^{0}$ \\
\hline 3. & $\begin{array}{l}\text { Taper } \\
\text { with } \\
\text { thread }\end{array}$ & 710 & 31.5 & $1^{0}$ \\
\hline
\end{tabular}

\section{RESULTS AND DISCUSSIONS}

\subsection{Micro Structural Observation:}

The micro structure specimen was taken from each specimen from its NG. The specimen's NG was super finished by using various emery papers and finally taken it into mirror image. Then after we go for etching we use killersreagent $\quad(2 \mathrm{mlHF}, 3 \mathrm{mlHCL}, \quad 20 \mathrm{mlHNO} 3$ and $175 \mathrm{mlH} 2 \mathrm{O}$ ) by optimal microscope as per ASTM E- 812 standards.The optical microstructures of the weld center are shown in fig below. The grain arrangement within the nugget is well and equiaxed and the grain size is significantly lesser than that in the base materials (5083) due to the advanced temperature and extensive plastic deformation by the stirring action of the tool probe. During FSW, the tool acts as a stirrer extruding the material along the welding path. Due to normal cooling the cooling rate of weldment was slower which impacts some uneven grains occur at some areas.

The recrystallization was strongly dependent on the rate of cooling and temperature. The fine grain size was obtained by circular tool with taper threaded at an welding parameters of $900 \mathrm{rpm}$ and $40 \mathrm{~mm} / \mathrm{min}$ of tool rotation speed and welding speed respectively. The micro structures of specins was showed in fig 4.1, 4.2, 4.3.

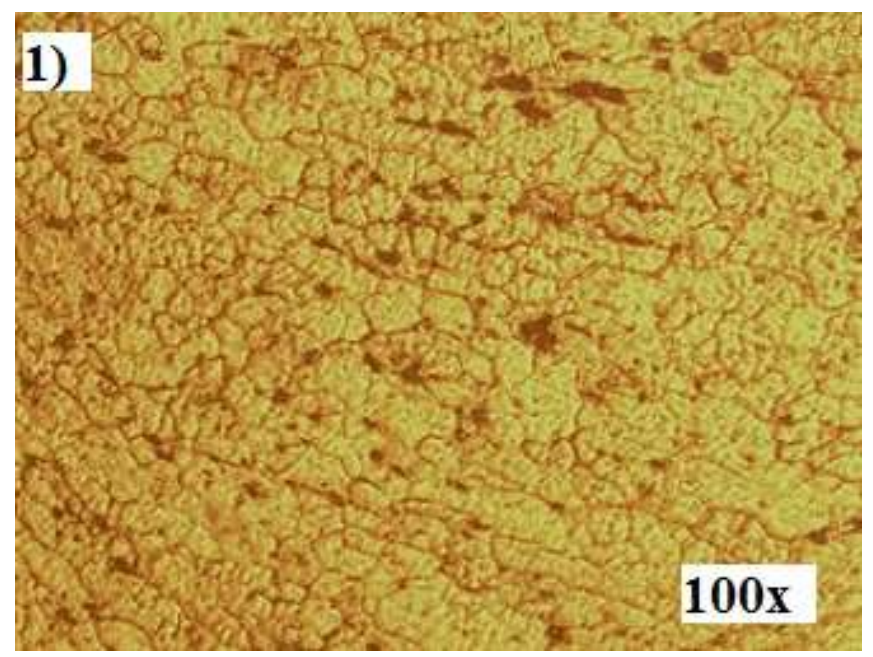

Fig:-4.1 micro structure of square probe tool at 1400rpm, $60 \mathrm{~mm} / \mathrm{min}$

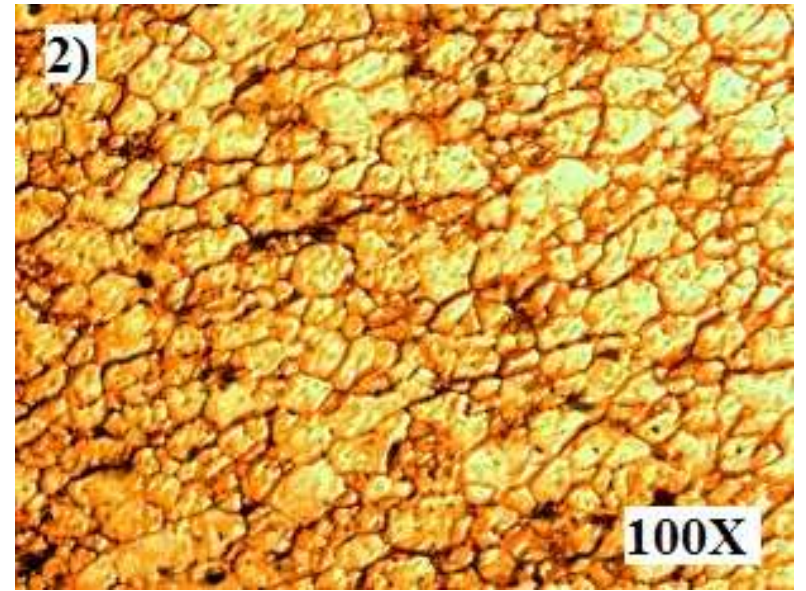

Fig -4.2: micro structure of circular with threaded probe tool at $900 \mathrm{rpm}, 40 \mathrm{~mm} / \mathrm{min}$

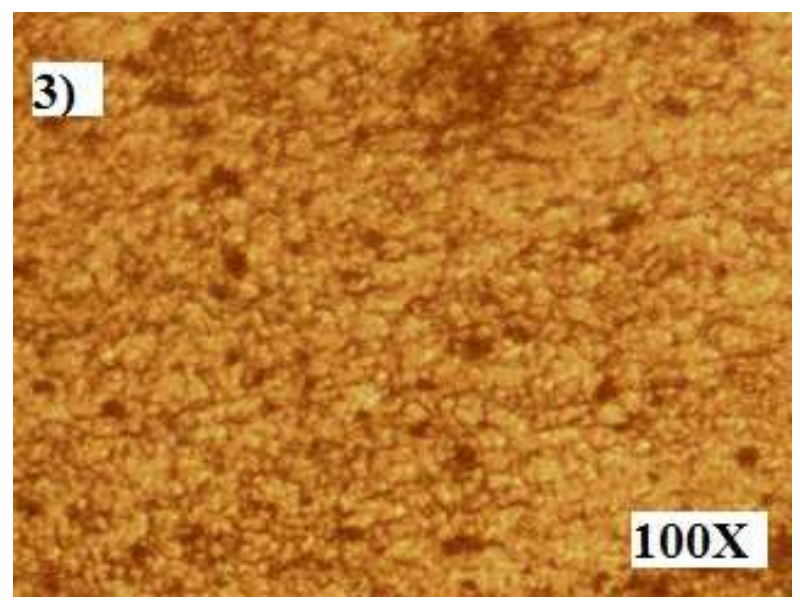

Fig -4.3: micro structure of circular with threaded probe tool at700rpm, $31.5 \mathrm{~mm} / \mathrm{min}$

\subsection{Mechanical Properties}

Two tensile samples were extracted from eachjoint. These samples were tested using universal testing machine (UTM) as per the ASTME 8-04 guidelines. The average of two readings is presented in Table 2 . The results show that the tensile properties of the welded joints are significantly varied with regard to different pin profiles. A higher tensile strength of $173.84 \mathrm{MPa}$ was attained in the joint made by square pin profiled tool. A lower tensile strength of $138.94 \mathrm{MPa}$ was attained in the joint made by taper with threaded pin profiled tool. Cylindrical with threaded pin profile results in the tensile strength of $172.79 \mathrm{Mpa}$. The percentage of elongation of welded joints was lower than that of the parent materials. The optimum proof stress was obtained with square pin tool.

Table-2: Tensile properties

\begin{tabular}{|l|l|l|l|}
\hline \multirow{2}{*}{$\begin{array}{l}\text { Specime } \\
\text { n }\end{array}$} & \multicolumn{4}{|l|}{ TENSILE PROPERTIES } \\
\cline { 2 - 4 } & $\begin{array}{l}\text { Ultimate } \\
\text { tensile } \\
\text { strength } \\
\text { (Mpa) }\end{array}$ & $\begin{array}{l}\text { \% } \\
\text { Elongation }\end{array}$ & $\begin{array}{l}\text { Yield } \\
\text { strength } \\
\text { (Mpa) }\end{array}$ \\
\hline 1 & 173.84 & 5.3 & 127.12 \\
\hline 2 & 172.79 & 7.32 & 101.86 \\
\hline 3 & 138.94 & 3.58 & 89.95 \\
\hline
\end{tabular}




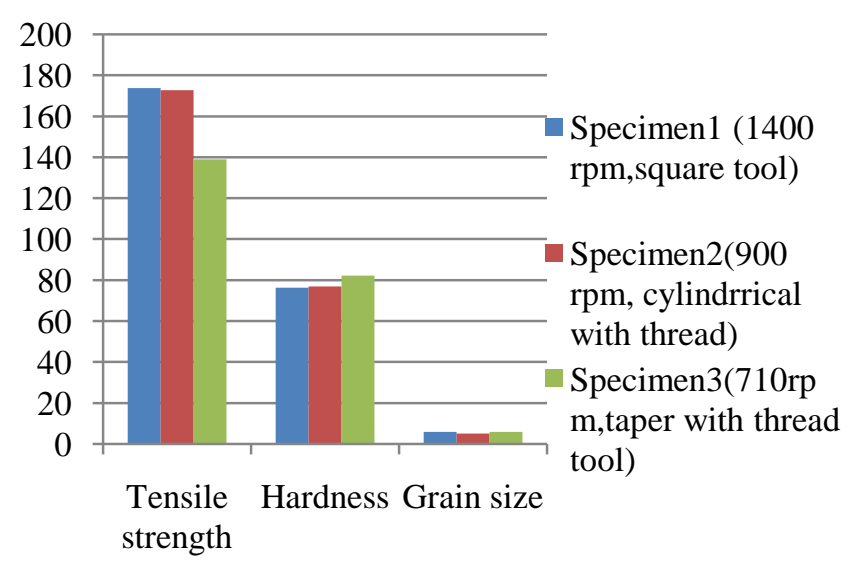

Chart-1 Evaluationof properties using bar graph.

\subsection{Vickers Hardness}

VICKERS HARDNESS: The Hardness properties of the specimens are carried under Vickers hardness testing machine as it is having diamond penetrator it is used to measure Additional depth.We took 3 readings for each specimen and the average values of hardness in the welding center (NG)were placed against different tool rotation speed in Table-3. It was observed that when rotation speed riseshardness in the weldmentdrops. The optimum value ofhardness was $82.13 \mathrm{HV}$ which was obtained by taper with threaded tool because of low tool rotation speed $(710 \mathrm{rpm})$ and welding speed $31.5 \mathrm{~mm} / \mathrm{min}$.

Table-3 Hardness and Impact (Charpy), Grain size properties

\begin{tabular}{|l|l|l|l|}
\hline Specimen & $\begin{array}{l}\text { Hardness } \\
(\mathbf{H V})\end{array}$ & Impact $(\mathbf{J})$ & $\begin{array}{l}\text { Grain } \\
\text { size }(\boldsymbol{\mu m})\end{array}$ \\
\hline 1 & 76.3 & 30 & 6 \\
\hline 2 & 76.87 & 30 & 5 \\
\hline 3 & 82.13 & 14 & 6 \\
\hline
\end{tabular}

\section{CONCLUSION}

As per review of papers, we can see that many of researchers have worked on joining of similar metal but very few works has been carried out on new advance dissimilar metal. Dissimilar metal joining process using friction stir welding is very difficult to achieve because of different coefficient of heat and the base metal chemical composition and their property make it difficult to choose a proper welding parameters like rotating speed, traverse speed, axial force and tilt angle which plays a vital role in improving the weld quality.

As per my experimental review I will conclude that

- The square pin tool weld was obtaining optimum tensile and yield strength values. 173.84MPa and 127.12MPa respectively. But the hardness value is low compared to other existed values. Because of tool high rotational speed(1400 rpm).

- The optimum elongation(7.32) value was obtained by circular with threaded tool.
- The optimum value of hardness was $82.13 \mathrm{HV}$ which was obtained by taper with threaded tool because of low tool rotating speed $(710 \mathrm{rpm})$ and welding speed 31.5 $\mathrm{mm} / \mathrm{min}$

\section{FUTUREWORK}

In order to further understand effect of welding parameters like rotational speed, traverse speed, axial force and tilt angle on these dissimilar aluminium alloys, i will go for a constant speed of $900 \mathrm{rpm}$ with welding speed of $40 \mathrm{~mm} / \mathrm{min}$ by using square pin tool and taper with threaded pin tool. Because these parameters give optimum values.

\section{ACKNOWLEDGMENTS}

We thanks to our college principal and our mechanical department staff and management for encouraging us and their continuous support during this work.SR Engineering College, Warangal for

\section{REFERENCES}

[1]. W.M. Thomas, E.D. Nicholas, J.C. Needham, M.G. Murch, P. Temple-Smith, C.J. Dawes, Method of operating on a workpiece, in, United States Patent, 5,460,317, The Welding Institute, Cambridge, GB, 1995.

[2]. E. Bousquet, A. Poulon-Quintin, M. Puiggali, O. Devos, M. Touzet, Relationship between microstructure, microhardness and corrosion sensitivity of an AA 2024-T3 friction stir welded joint, Corrosion Science, 53 (2011) 3026-3034.

[3]. M. Ericsson, R. Sandström, Influence of welding speed on the fatigue of friction stir welds, and comparison with MIG and TIG, International Journal of Fatigue, 25 (2003) 1379-1387.

[4]. M. Jariyaboon, A.J. Davenport, R. Ambat, B.J. Connolly, S.W. Williams, D.A. Price, The effect of welding parameters on the corrosion behaviour of friction stir welded AA2024-T351, Corrosion Science, 49 (2007) 877-909.

[5]. R.A. Prado, L.E. Murr, D.J. Shindo, K.F. Soto, Tool wear in the friction-stir welding of aluminum alloy $6061+20 \%$ Al2O3: a preliminary study, ScriptaMaterialia, 45 (2001) 75-80.

[6]. S. Benavides, Y. Li, L.E. Murr, D. Brown, J.C. McClure, Low-temperature friction-stir welding of 2024 aluminum, ScriptaMaterialia, 41 (1999) 809-815.

[7]. J.Q. Su, T.W. Nelson, R. Mishra, M. Mahoney, Microstructural investigation of friction stir welded 7050T651 aluminium, ActaMaterialia, 51 (2003) 713-729.

[8]. B. Yang, J. Yan, M.A. Sutton, A.P. Reynolds, Banded microstructure in AA2024-T351 and AA2524-T351 aluminum friction stir welds: Part I. Metallurgical studies, Materials Science and Engineering: A, 364 (2004) 55-65.

[9]. M.A. Sutton, A.P. Reynolds, B. Yang, R. Taylor, Mode I fracture and microstructure for 2024-T3 friction stir welds, Materials Science and Engineering: A, 354 (2003) 6-16. 23. [10]. M.J. Jones, P. Heurtier, C. Desrayaud, F. Montheillet, D. Allehaux, J.H. Driver, Correlation between microstructure and microhardness in a friction stir welded 2024 aluminium alloy, ScriptaMaterialia, 52 (2005) 693697. 
[11]. A. Sullivan, J.D. Robson, Microstructural properties of friction stir welded and post-weld heat-treated 7449 aluminium alloy thick plate, Materials Science and Engineering: A, 478 (2008) 351-360.

[12]. C. Genevois, A. Deschamps, A. Denquin, B. Doisneau-cottignies, Quantitative investigation of precipitation and mechanical behaviour for AA2024 friction stir welds, ActaMaterialia, 53 (2005) 2447-2458.

[13]. T.R. McNelley, S. Swaminathan, J.Q. Su, Recrystallization mechanisms during friction stir welding/processing of aluminum alloys, ScriptaMaterialia, 58 (2008) 349-354.

[14]. M.A. Sutton, B. Yang, A.P. Reynolds, R. Taylor, Microstructural studies of friction stir welds in 2024-T3 aluminum, Materials Science and Engineering: A, 323 (2002) 160-166.

[15]. J.B. Lumsden, M.W. Mahoney, C.G. Rhodes, G.A. Pollock, Corrosion Behavior of Friction-Stir-Welded AA7050-T7651, Corrosion, 59 (2003) 212-219. 